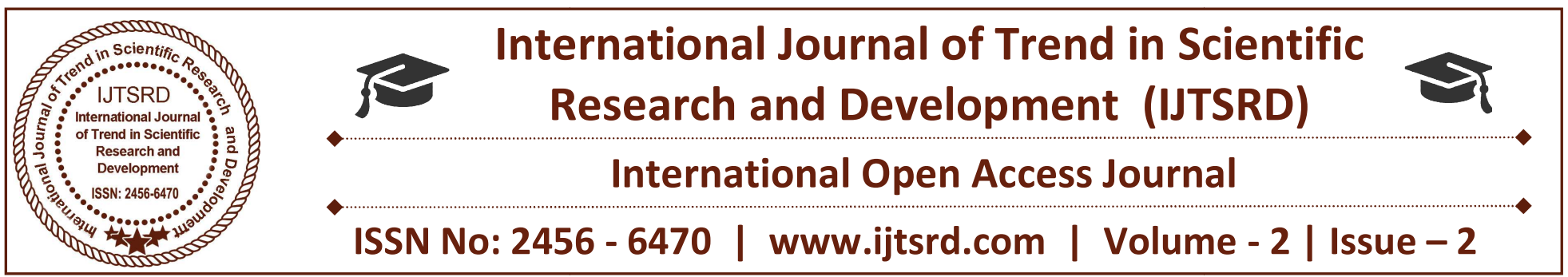

\title{
Comparative Study of Hybrid Fiber Reinforced Concrete Deep Beam under Shear
}

\author{
Mr. Shelke A. S, Ms. Kognole R. S \\ Assistant Professor, Department of Civil Engineering, \\ Bhivarabai Sawant College of Engineering and Research, Narhe, Pune, Maharastra, India
}

\section{ABSTRACT}

As per the Indian standard a beam shall be considered as deep beam when the ratio of effective span to overall depth is less than 2 for simply supported \& 2.5 for continuous beam. Deep beam transfer the load by shearing action rather than flexural action. Shear strength of concrete beam is not well defined as it is complex phenomenon. To improve shear strength \& deformation of cement matrix mixed (Crimped steel Polypropylene) fibers are used. By adding steel fiber it is observed that crack resistance and crack control is improved. Also polypropylene fiber is improving compressive strength, shear strength, resistance to aggressive agents, micro crack control. Therefore we use hybrid fibers (Crimped steel - Polypropylene) as reinforcement in concrete to improve homogeneous, isotropic characteristics, Tensile $\&$ shear response by arresting micro crack, crack penetration \& propagation. The several recently published articles \& technical papers dealing with implementation of hybrid fibers in concrete matrixes.

Keywords: Shears strength, mixed (Crimped steelPolypropylene) fibers, Deep Beam, Diagonal tension, Concrete, compressive strength, Cracks

\section{INTRODUCTION}

As per the bureau of Indian standard code method the deep beam is a beam having a ratio of clear span to depth is less than 2 for simply supported beam \& 2.5 for continuous beam, which transfer heavy gravity load primarily through shearing action by forming a diagonal cracks.

In long span beam failure occurs due to flexural failure, as bending stress is more than shear stress. Deep beams fails in shear as bending stress is below the ultimate flexural capacity of the beam. A effect of these is that the plane section do not remain plane $\&$ perpendicular to the neutral plane after deformation. The shear action in the deep (web) beam is predominant. There deep beam may fail in diagonal failure \& bearing failure.

To decrease the brittleness \& increase the resistance to cracking, reinforcement with short randomly distributed fibers has been successfully used \& final composites is known as fiber reinforced concrete (FRC). The performance of FRC depends on many factors such as fiber material properties, fiber geometry, fiber volume, matrix property \& interface properties. Most type of FRC used in practice contains only one type of fiber i.e. steel fiber. In concrete a small cracks is always presents in orders of micron. The rapid fracture $\&$ unstable propagation is occurred due to the conversion of micron crack into the micro crack by increasing \& joining the cracks to each other when external load is applied on them. Therefore for good result different types of fibers may combine. Steel fibers can be used either to boost the shear capacity or to replace the web reinforcement in conventional RCC deep beams \& synthetic fibers can be used to control the micro cracks. Therefore the objective of these work is to study the effect of 
addition of different percent of mixed fibers (crimped steel-Polypropylene) varying clear span to depth ratio.

\section{SUMMARY OF PREVIOUS RESEARCH}

There are various research papers on the deep beam related it's flexural \& shear strength. Actually a research was mostly done on flexural strength as compared to shear strength. Due to these shear strength in reinforced concrete deep beams has been the subject to many controversies \& debates since the beginning of $20^{\text {th }}$ centuries. We are collect the information from various journals, research papers etc. some of them are discussed below.

\subsection{REVIEW PAPER}

A) Roberts:-

In these paper Roberts studied the behavior of deep beams under shear failure \& results of a number of tests on deep fiber reinforced concrete beam were presented.

In these beam longitudinal reinforcement used in constant rate and in place of conventional shear reinforcement different percentage of steel fibers is used. All beams are tested under two point loading. He use the $0.38 \mathrm{~mm}$ diam. \& $38 \mathrm{~mm}$ long "Duoform" brass coated steel fibers. A single $16 \mathrm{~mm}$ diam. HYSD deformed bar is used as a longitudinal reinforcement, A concrete of a grade 39 mpa to 48 mpa is used throughout the experiment. He made a three sets of specimens were made with $0 \%, 0.85 \%$, $1.3 \%$ by volume of steel fibers with each set consist of 3 beam.

The result obtained after testing the beam specimen indicate that the inclusion of steel fibers in the concrete increases the ultimate flexural capacity \& also resistance to shear failure.

\section{B) Krishna Rao:-}

To study the behaviours of moderate deep beams in shear \& flexure Krishna Rao use additional material polypropylene fiber \& replacing $20 \%$ fly ash for cement.

For overall Experiment he done a following things. The clear span to depth ratio used hears is 2.0. To check the behaviour of deep beam in shear and flexure strength polypropylene is used in three stages in different percentages such as $0 \%, 0.5 \%, 1 \%$ with the three different grades of concrete is $15 \mathrm{mpa}, 20$ mpa, \& 25 mpa. The $20 \%$ of cement is replaced by using the fly ash.

As comp strength of concrete specimen increases with the increasing percentage of fibers. Also shear \& flexural strength of beam specimen is increases from $0 \%$ to $1 \%$ fibers. In this case the ultimate failure is observed as a gradual not a sudden.

\section{C) Ramadevi:-}

Ramadevi state that the analysis the behavior of $\mathrm{RC}$ beam is strengthens by using mixed fiber reinforced concrete (HFRC).

As per 10262-2009beam is casted for M-25 grade of concrete. The mixed fibers used are polyolefin \& steel (crimped) fibers in various proportion from $0.5 \%, 1 \%$, $1.5 \% \& 2 \%$ of volume of concrete. The admixture used in these is superplastisizer conplast SP 3370 for achieving desired workability.

During lading \& deflection of fiber specimen mixed fibers increase the flexural strength as compared to original specimen.

D) S. K. Madan \& S. P.Singh:-

Singh \& S. K. Madan replace the web reinforcement by using steel fibers for reinforced concrete deep beam in shear.

For this purpose he casted total 18 beams which tested under two point top loading up to failure. He use a straight steel fibers having a diameter $0.45 \mathrm{~mm}$, length $40.5 \mathrm{~mm} \&$ aspect ratio with three volume fraction $(0 \%, 1 \%, 1.25 \%) \&$ three shear span to depth ratio $(0.75,1.0,1.25)$ All beams were of rectangular cross section, $90 \mathrm{~mm}$ wide \& $260 \mathrm{~mm}$ deep, $700 \mathrm{~mm}$ long with 2 bars of $10 \mathrm{~mm}$ diameter as a longitudinal reinforcement. The clear span to overall depth ratio varies from 1.69 to $2.5 \mathrm{M}-20$ grade of concrete is used through the whole experiment.

The test result shows that the use of short steel fibers in concrete mix provides clear shear reinforcement in deep beams \& provides better crack control \& deformation. Both the First crack \& ultimate crack strength in shear also increased.

E) S. P .Singh \& A. P. Singh \& V. Bajaj:-

Sigh \& bajaj evaluate the strength \& flexural toughness of mixed fiber reinforced concrete (HFRC) 
containing different combinations of steel \& polypropylene fibers.

To obtain the flexural strength under four point static flexural loading beam specimens of size $100 \mathrm{~mm} x$ $100 \mathrm{~mm} \times 500 \mathrm{~mm}$ is used. In addition to obtain a compressive strength of concrete cube specimen of size $150 \mathrm{~mm} 150 \mathrm{~mm} 150 \mathrm{~mm}$ which is also tested. In the specimen steel \& polypropylene fibers are used in the mix proportions of $100-0 \%, 75-25 \%, 50-50 \%, 25-$ $75 \%, 0-100 \%$ by volume of a total volume fraction of $1 \%$. He uses corrugated steel fibers $35 \mathrm{~mm}$ long, 2 $\mathrm{mm}$ wide \& $0.6 \mathrm{~mm}$ in thickness \& homo-polymer fibrillated polypropylene fibers. In HFRC to increase comp strength, flexural strength \& flexural toughness a fiber combination of $75 \%$ of steel fibers plus $25 \%$ of polypropylene fibers is used to give appropriate result.

F) Venu R. Patel, Pandya:-

Venu R. Patel \& Pandya study the shear strength of Polypropylene Fibre Reinforced Concrete (PPFRC) moderate deep beams without stirrups.

For that he use a beam having a span to depth ratio $2.0,2.4,3.0,4.0$. He casted \& tested total 16 numbers of beams out of this 4 numbers of beams were tested to failure under two point symmetrical loading and 12 numbers of beams were tested to failure under central point loading. During loading of whole experiment Venu patel study complete shear deformational behaviour along with load-deflection response, crack patterns and modes of failure. Venu patel evaluate the ultimate shear strength from the experimental results \& compared with shear strength obtained from various empirical equations.

These comparison shows that the shear strength obtained by experimentally give more accurate result. Polypropylene fibres can be used to replace stirrup partially with proper design of concrete.

\section{G) Abhishek Kumar Singh, Anshul Jain and Deependra Singh:-}

The intent of this research is to investigate and compare the compressive and flexural strength of concrete for various mixture proportion of concrete.

For increasing tensile and flexural strength of concrete fiber reinforced concrete is a largely used. There are various types of fibers such as steel, polypropylene, glass and polyester are mostly used in concrete. So Abhishek kumar singh is study the effect of addition of polypropylene and steel fibers on the compressive and flexure strength of fiber reinforced concrete. For that he use a Polypropylene \& steel fibers in varying proportion i.e. Polypropylene fibers use in $0 \%$ to $0.45 \%$ \& steel fibers of $0 \%$ to $2 \%$ by volume of concrete.

The test results clarified that use of polypropylene and steel fibers at $0.15 \%$ and $1 \%$ respectively showed considerable increase in strength of $47.10 \mathrm{MPa}$ and $58.20 \mathrm{MPa}$ at 7 and 28 days respectively. The behaviour of concrete under flexural loads was found to be consistently improved compared with reference mix design.

\section{METHODOLOGY}

Methodology to be adopted is

1] To find out design of M-50 grade of concrete by performing all basic test on cement, sand \& aggregate as per IS code.

2] Casting a RCC deep beams by varying fiber volume fraction $(0 \%, 2 \%$, and $3 \%) \&$ clear span to depth ratio $(1.98,1.84 \& 1.72)$

3] Testing these RCC deep beams under two point loads for shear failure.

4] To investigate the effects of addition of hybrid (Crimped steel - Polypropylene) fibers to concrete in compression.

5] To investigate the effects of addition of hybrid (Crimped steel - Polypropylene)fibers to concrete in shear.

\section{CONCLUSION}

This paper describes the implementation of the mixed (Crimped steel - Polypropylene) fibers in to the concrete then First crack shear strength \& ultimate shear strength increases with increasing percentage of fibers. The compressive strength is also increased with increasing fibers percentage is checked by casting cubes. It also improves the strength \& deformation characteristics of cement base matrixes. By using steel fibers we also eliminate the conventional stirrups in some percentage. Mixed (Crimped steel - Polypropylene) fibers achieve all these things by converting brittle cement matrixes in to the ductile material by arresting a micro cracks \& resistance to crack propagation. 


\section{REFERENCES}

1) T. M. Roberts \& N. L. Ho (1982). "Shear failure of deep fiber reinforced concrete", The International Journal of Cement Composites and Lightweight Concrete, Vol-4, pp. 145-152.

2) M.V. Krishna Rao, N.R. Dakhshina Murthy and V. Santhosh Kumar "Behaviour of Polypropylene fibre reinforced Fly ash concrete deep beams in Flexure \& Shear" ASIAN JOURNAL OF CIVIL ENGINEERING (BUILDING AND HOUSING) VOL. 12, NO. 2 (2011)

3) K. Ramadevi \& D. L. Venkatesh Babu "Flexural Behavior of Hybrid (Steel-Polypropylene) Fibre Reinforced Concrete Beams" European Journal of Scientific Research ISSN 1450-216X Vol.70 No.1 (2012), pp. 81-87 C EuroJournals Publishing, Inc. 2012

4) S. K. Madan, G. Rajesh Kumar and S. P. Singh (2007). "Steel fibers as replacement of web reinforcement for RCC deep beams in shear", Asian Journal of Civil Engineering, Vol-8(5), pp. 479-489.

5) Vinu R. Patel, Pandya "Ultimate shear strength of Fibrous moderate deep beams without stirrups" Int. Journal of Applied Sciences and Engineering
Research, Vol. 1, No. 2, 2012 (C) 2012 by the authors - Licensee IJASER- Under Creative Commons License 3.0 Research article

6) Abhishek Kumar Singh, Anshul Jain and Deependra Singh " Evaluation Of Mechanical Properties For Polypropylene And Steel Fiber Reinforced Concrete" International Journal of Engineering Research \& Technology (IJERT) Vol. 2 Issue 4, April - 2013 ISSN: 2278-0181

7) Emma Slater, Moniruzzaman Moni and $M$. Shahria Alam (2012). "Predicting the shear strength of steel fiber reinforced concrete beams", Construction of Building Materials, Vol-26, pp. 423-436.

8) Vengatachalapathy (2010). "Behavior and ultimate strength of steel fiber reinforced concrete (SFRC) deep beams with and without openings", International Journal of Civil and Structural Engineering, Vol-1(3), pp. 509-517.

9) Londhe R. S. (2010) Experimental investigation on shear strength of SFRC beams reinforced with longitudinal tension steel rebar's: Asian Journal of Civil Engineering and Housing, 11(3):385-395. 